\title{
Geochemical Investigation of Vertical Migration of Petroleum through Mudstones I: Origin of the Hydrocarbon Shows
}

\author{
1Mohammed Bello Adamu and 2Aminu Bayawa Muhammad \\ 1 Petroleum Engineering Programme, School of Engineering and Engineering Technology, \\ Abubakar Tafawa Balewa University, P.M.B. 0248, Bauchi, Nigeria
}

2Department of Pure \& Applied Chemistry, Usmanu Danfodiyo University, PMB 2346 Sokoto, Nigeria

[Corresponding author: Email belloadamu@yahoo.com; 푱+2348180668268]

\begin{abstract}
Hydrocarbon shows and seeps are frequently associated with petroleum migration through caprocks. However, leakage of petroleum from reservoirs does not necessarily result in surface seeps, nor do all occurrences of surface petroleum result from trap leakage. Cretaceous Shetland Group mudrocks which serves as caprock (seal) for the petroleum reservoir of the Heidrun Field was observed to contain liquid hydrocarbon as evidenced from UV florescence. Is this oil indigenous of the caprock or from the underlying reservoir thereby indicating possible failure of the seal? Samples from the caprock were analysed with the aim of establishing the origin of the oil stains. The investigation comprised bulk geochemical analyses in order to estimate various leakage indicators (S1 \& PI). High Extractable Organic Matter (EOM) values of up to $6 \mathrm{mg} / \mathrm{g}$ rock were obtained in most of the samples. The high S1 and PI values obtained from the samples suggest oil staining. Furthermore, latroscan SARA analysis was used to identify compositional variability between the oil present in the caprock and the reservoir oil. The reservoir oil predominantly consisted of saturated hydrocarbons, which, in contrast, represent only a fraction of the caprock EOM. The caprock EOM is dominated by polar compounds, and the saturate fraction increases with increasing proximity to the caprock/reservoir boundary. High gas wetness of more than $80 \%$ was recorded at caprock/reservoir boundary, suggesting a good relationship between the distribution of gaseous hydrocarbons in the caprock and the gas content of the reservoir oil. The oil stains in the caprock are therefore established to be sourced from the reservoir.

Keywords: Leakage; Mudrock; Extractable organic matter; Production index; Gas wetness
\end{abstract}

\section{INTRODUCTION}

Petroleum leakage is one of the key factors in assessing the petroleum prospect of a field, for both hydrocarbon systems analysis and reservoir quality predictions (England et al., 1987). Therefore, a good understanding of the mechanisms by which petroleum leakage occurs is fundamentally important for a successful petroleum exploration and prospect appraisal.

Caprocks (mudstones) provide potential energy barrier to petroleum leakage (England et al., 1987). The caprock seal capacity of a formation immediately overlying a hydrocarbon-charged reservoir is vital to the determination of a prospect's productivity, as well as to the migration and reservoir studies (Schowalter, 1979). Mudstones often form effective cap rocks to petroleum accumulations (Landes, 1981) because they have very low permeabilities, and reduced pore throat radii resulting in high capillary entry pressures compared to reservoir rocks. Furthermore, such mudstones are typically continuous across a basin thereby providing an extensive lateral seal to the reservoired oil (Ingram et al., 1997). This, however, does not mean such a mudstone seal could not be breached.

According to Clarke and Cleverly (1991) although most seeps appear to mark site of fracture pathways in petroliferous basins which have been subjected to intense deformation, surface leakage of petroleum does not necessarily results in surface seeps, nor do all occurrences of surface petroleum results from trap leakage. Schowalter (1979) and Schowalter and Hess (1982) subdivided leakage shows into four types: (1) Type I- continuous phase oil and gas; (2) Type IIisolated droplets of oil and gas (residual shows); (3) Type III- molecular scale dissolved hydrocarbon phase, and; (4) Type IV- hydrocarbons associated with kerogen. Each show type has a different exploration implication. Residual shows are the most important in terms of caprock failure, as they provide evidence of oil staining following oil and gas migration (Schowalter and Hess, 1982).

Gas chimneys or seismic chimneys are commonly interpreted to mark sites of petroleum leakage. For 
example, the presence of well defined seismic chimneys over faults in an overpressured zone in the western part of Haltenbanken (Vik et al., 1989) suggests that oil may be leaking through the Heidrun caprock. Although gas chimneys are sometimes situated above hydrocarbon accumulations, they are also related to water-filled structures and therefore do not necessarily indicate petroleum leakage. Gas chimneys may also be the result of processes that operate in both hydrocarbon-filled and water filled structures (Bjorkum et al., 1998). They suggest that gas chimneys should be interpreted as the focal point for the upward drainage of fluids.

In general, for comprehensive understanding of whether or not identified oil stain on the surface or in a formation overlying a charged reservoir occurrs as a result of leakage, geochemical investigation is necessary. The basic principle involves comparing the seep and reservoired oil to establish whether they are genetically related in addition to assessing the thermal maturity of the mudrock seal to establish whether the resident oil could be indigenous. In the light of this we here report the geochemical investigation we conducted on a number of selected caprock samples from the Shetland Group within the Heidrun Field in the Haltenbanken area, offshore Norway with the aim of establishing the source of the oil present in the caprock as well as evaluating whether a definite genetic link exists between the reservoir oil and that present in the caprock i.e. establish whether the caprock sealing capacity is breached.

\section{MATERIALS AND METHODS \\ The study area}

The Heidrun Field is located in the Haltenbanken area of Norwegian sector of the North Sea. The Haltenbanken area is part of a passive continental margin between the Møre Basin and the Trøndelag Platform and represents a southern extension of the Nordland Ridge (Figures. 1A and B). The Heidrun field is located at a water depth of 350 meters in the North Sea, and lies $175 \mathrm{~km}$ West of Kristiansund and approximately $190 \mathrm{~km}$ off the coast of mid-Norway (Whitley, 1992).

The Heidrun has recoverable reserves of $750 \mathrm{MMB}$ of oil, $0.45 \mathrm{tcf}$ of associated gas, and $1.32 \mathrm{tcf}$ of primary (free) gas at the start of production in October 1995 (Whitley, 1992). Its production in 2006 was estimated at $3 \mathrm{Mm}^{3}$ gas and 140,000 barrels of oil a day. The gas-to-oil ratios (GORs) vary widely amongst different wells ranging from $2636 \mathrm{~m}^{3} / \mathrm{m}^{3}$ in the Tofte Formation to $48 \mathrm{~m}^{3} / \mathrm{m}^{3}$, in the Tilje Formation (Karlsen et al., 1995).

The main source rock for the Heidrun Field is considered to be the Upper Jurassic Spekk Formation (Figure. 1B), which contain amorphous Type II with some Type III kerogen, formed from marine deposition of the Melke shales during the Callovian. It is a rich source rock with a total organic carbon (TOC) of up to $13 \%$ (mean 4\%; Whitley, 1992). It is a highly favourable source for oil, with a gas/oil generation index (GOGI) of about 0.19. Two other formations are considered to be adequate source rocks: the Ảre Formation (Lower Jurassic), which has a Type II/III kerogens, indicated to have a GOGI in the range of about 0.33; and the Melke Formation, generally considered to have an insignificant oil potential compared to both the Spekk Formation and the deeper Ảre Formation (Karlsen et al., 1995).

The petroleum accumulations in the Heidrun field and in other parts of the Haltenbanken region have been found to be structurally related to horsts or rotated fault blocks (Karlsen et al., 1995). The main reservoir units of the Heidrun Field are the sands of the Jurassic Fangst Group consisting of the lle, Not and Garn Formations (Figure 1B). There is significant variation in the thickness of these units due to the synsedimentary faulting and erosion associated with the Cinemerian Fault movements (Whitley, 1992)

The Heidrun reservoir is capped by the Upper Cretaceous of the Shetland Group mudstones that resulted from the continued subsidence and basin fill in the Cretaceous and Tertiary providing an effective seal and sufficient overburden for thermal maturation (Whitley, 1992).

\section{Description of the samples}

Samples used included rock cuttings and side wall cores. Twenty two shale rock samples were collected from the reservoir/caprock boundary through to the top of the caprock formation to allow comparison between reservoir oil and oil in the caprock and to monitor any compositional similarity or variability (Table 1).

The samples were selected from two wells: (1) the crest of the structure (the Nise Formation, Figure 1), and; (2) flank/side of the structure (the Springer Formation, Figure1). The rationale for this was to obtain the basis 
for a comparison between caprock failure at the crest of the structure, where oil column buoyancy is at a maximum, and at an off-crest position where the oil leg is thinner and the buoyancy is therefore relatively low. Two additional oil samples from the reservoir were also used in the study with the intent of unravelling any genetic link with the oil observed in the caprock.

\section{Total carbon (TC) and total organic carbon (TOC)}

The total carbon (TC) and total organic carbon (TOC) content of the samples were measured using a LECO CS244 Carbon/Sulphur analyser. About $100 \mathrm{mg}$ of the sample, in crucible, was treated with $6 \mathrm{M}$ aqueous hydrochloric acid. The crucible was allowed to stand until all the acid drained. De-ionised water was then added to drain the excess acid. The washing was repeated five more times to ensure all the excess acid was removed. Thereafter, the samples were dried at $65^{\circ} \mathrm{C}$ for 24 hours. Blanks were prepared similarly except without sample. In each case, average of two replicates was recorded.

\section{Rock-Eval pyrolysis}

The Rock-Eval pyrolysis was carried out according to the methods of Peters (1986) using an Oil Show Analyser. Briefly about $100 \mathrm{mg}$ of the sample was weighed into a crucible and pyrolysed in a stream of helium gas. Initially, the temperature was raised to $100^{\circ} \mathrm{C}$ and held for 1 minute, to measure volatile (gaseous) hydrocarbons as $\mathrm{S} 1$ (mg/g Rock). Then the temperature was increased at $25^{\circ} \mathrm{C} /$ minute to $300^{\circ} \mathrm{C}$ and held for 2 minutes to record the free liquid hydrocarbons as $\mathrm{S} 2$ (mg/g Rock). Finally, the temperature was raised at $25^{\circ} \mathrm{C} /$ minute to $550^{\circ} \mathrm{C}$ and held for 1.5 minutes to measure hydrocarbon pyrolysate from the nonvolatile organic matter as S3 (mg/g Rock). The production index $(\mathrm{PI})$, was obtained from equation 1 (Espitalie et al., 1985; Peters, 1986).

$$
\mathrm{PI}=\mathrm{S} 1 /(\mathrm{S} 1+\mathrm{S} 2)
$$

\section{Extraction of samples}

The crushed sample $(300 \mathrm{mg})$ was extracted using Soxhlet apparatus with an azeotropic mixture of dichloromethane: methanol (93:7) for 24 hours In the presence of activated copper for removal of elemental sulphur. Solvent was removed from the extract by rotary evaporation at reduced pressure $\left(20\right.$ mbar, $\left.30{ }^{\circ} \mathrm{C}\right)$ until about $5 \mathrm{ml}$ was left. Further removal of the solvent was done under stream of nitrogen to avoid loss of the low molecular weight hydrocarbons.

\section{Fractionation of sample extracts}

A solid phase extraction (SPE) technique was used to separate the hydrocarbon and polar fractions of the extracts (Bennett \& Later, 1997; Larter et al., 1996). About $50 \mathrm{mg}$ the extract (EOM) were dissolved in $n$-hexane and transferred to an octadecyl $\left(\mathrm{C}_{18}\right)$ non end-capped (NEC) SPE column $(500 \mathrm{mg} / 3 \mathrm{ml}$, Isolute). The hydrocarbon fraction, containing the aliphatic and aromatic hydrocarbons, was eluted with $5 \mathrm{ml}$ hexane and the polar fraction was eluted with $6 \mathrm{ml}$ DCM. The hydrocarbon fractions were analysed by GC.

\section{Gas Chromatography (GC)}

The Total hydrocarbon fractions and the non-hydrocarbon fractions were analysed using a Carlo Erba 5160GC with automatic sampler, flame ionisation detector and fitted with a DB-5 fused silica capillary column $30 \mathrm{~m} \times 0.32 \mathrm{~mm}$ i.d. $x 0.25 \mu \mathrm{m}$ film thickness. The oven was temperature programmed at $40^{\circ} \mathrm{C}$ (held for 2 minutes) and then ramped at $4^{\circ} \mathrm{C} / \mathrm{min}$ to $300^{\circ} \mathrm{C}$ where it was held for 20 minutes.

\section{latroscan (TLC-FID)}

The relative proportions of saturated hydrocarbon, aromatic hydrocarbon, resins and asphaltenes (SARA) fractions of the extracts (EOM) from the rock samples and the two reservoir oils were determined using lotroscan in accordance with the method of Karlsen and Later (1991). The extract, dissolved in DCM, was applied to a type III Chromarod in duplicates and then fractionated by sequential development in hexane (to $100 \%$ rod height, dried for 3 minutes), toluene (to $40 \%$ rod height, dried 6 minutes) and then finally in $\mathrm{DCM} / \mathrm{methanol}$ (to $30 \% \mathrm{rod}$ height, dried $1.5 \mathrm{~min}$ at $60^{\circ} \mathrm{C}$ ). The separation was monitored using a standard solution containing squalane, anthracene and undecanol, and Brent oil as standard oil.

\section{Correction of EOM for "light-end loss"}

The amounts of EOM obtained were corrected in order to account for loss of the light $n$-alkanes $\left(n \mathrm{C}_{1}-n \mathrm{C}_{15}\right)$ during sample handling and analysis (Cooles et al., 1986). The light hydrocarbons lost were corrected according to Pepper and Corvi (1994) correlation between the API gravity of oil and the weight percent of the $n \mathrm{C}_{12}$ - fraction in the crude oils. They suggest that the $n \mathrm{C}_{12}$-fraction of oil, with an API gravity of 35 , is approximately $35 \%$. Therefore, oils with API gravity greater than 35 have much larger $n \mathrm{C}_{12+}$ fraction, than those with lower API gravity. A reasonable correction can therefore be made for a reservoir with a known API gravity. Thus the amounts of EOM obtained from the solvent extraction of the Heidrun caprock is assumed to have lost the $\angle n \mathrm{C}_{15+}$ components through evaporation during storage and analysis. This approximation was used when correcting for the measured EOM in the Heidrun caprock. 


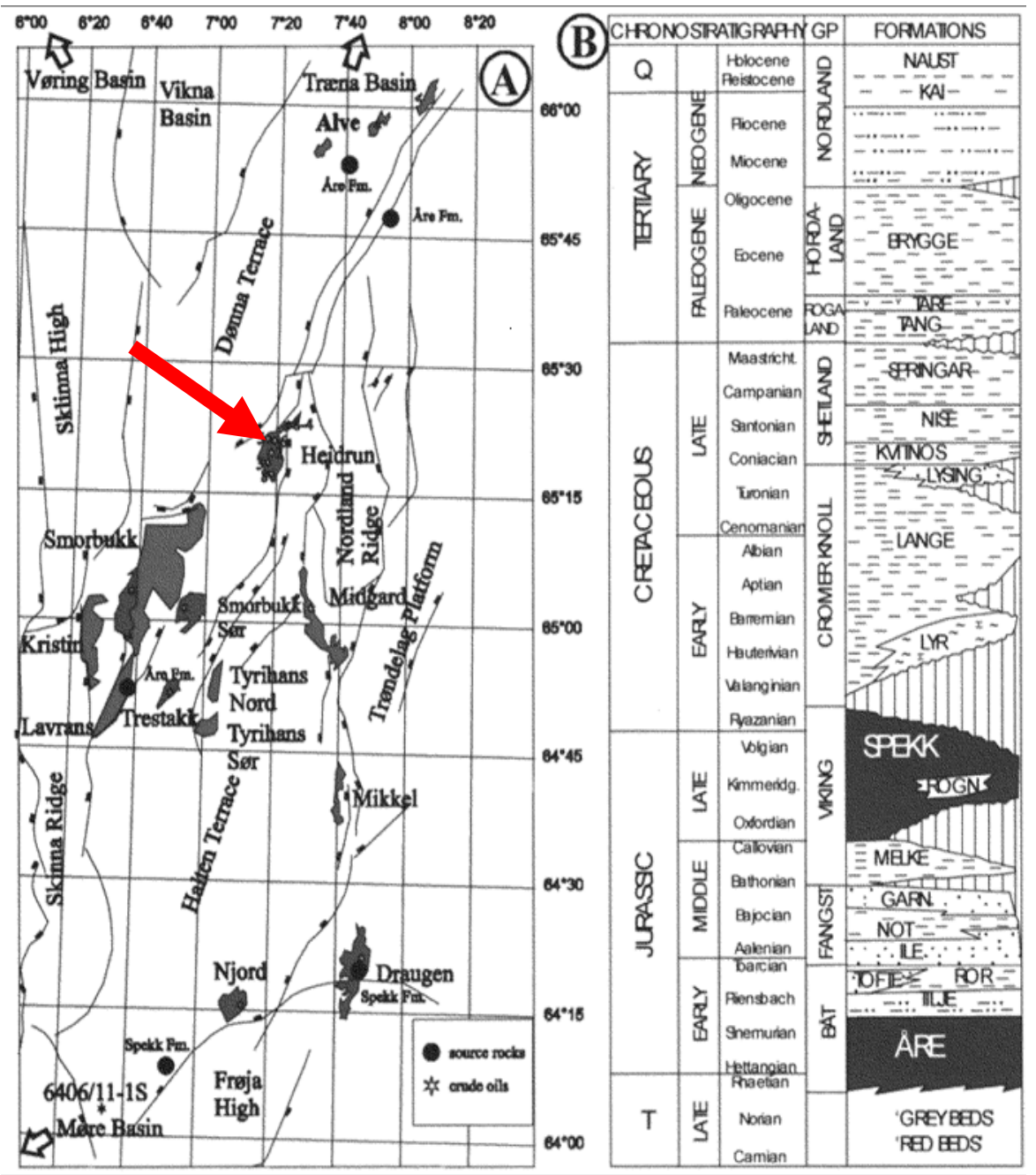

Figure 1: (A) Map of the Haltenbanken showing the study area (Heidrun field); and (B) the stratigraphic map of the Heidrun describing the reservoir and caprock formations 
Nigerian Journal of Basic and Applied Science (June, 2015), 23(1): 65-74

Table 1: List of Samples Used in the Study and their Respective Lithological Descriptions

\begin{tabular}{llll}
\hline Sample & Position & Depth $(\mathbf{m})$ & Rock description/comments \\
\hline C1 & Flank & 2060 & Mid + light grey siltstone + fine sandstone \\
C2 & Flank & 2070 & Mid + light grey siltstone + fine sandstone \\
C3 & Flank & 2120 & Mid + grey siltstone/v.f. sandstone coating \\
C4 & Flank & 2130 & mid-grey siltstone/v.f. sandstone coating \\
C5 & Flank & 2140 & mid-grey siltstone/v.f. sandstone coating \\
C6 & Crest & 2056 & Light/mid/dark grey flakey shales/siltstones, some greenish. Trace. calcite, \\
C7 & Crest & 2059 & Myrite, sandstone grains \\
C8 & Crest & 2062 & As above but fewer wisps \\
C9 & Crest & 2065 & Mid-grey mudstone, soft uniform. Some fluffy white wisps \\
C10 & Crest & 2068 & Mainly light grey + small amount mid/dark grey shale. pyrite, quartz, carbonate \\
C11 & Crest & 2071 & Mid/light grey mudstone. Some fines \\
C12 & Crest & 2074 & Mid/light grey mudstone+ some green mudstone. Mainly fines \\
C13 & Crest & 2077 & Mid + light grey mudstone, quartz grains, siltstone, small amount of mica. \\
C14 & Crest & 2080 & Mainly fines \\
C15 & Crest & 2083 & Mid + light grey mudstone + small amount walnut. Mainly fines \\
C16 & Crest & 2089 & Mainly soft lt.grey+20\%dark grey mudstone. \\
C17 & Crest & 2101 & Mix light and dark grey mudstone. Much harder than above \\
C18 & Crest & 2107 & Mix light and dark grey mudstone. \\
C19 & Crest & 2119 & Light grey mudstone. Soft with some hard grey mudstone pieces \\
C20 & Crest & 2128 & Light grey mudstone. Soft with some hard grey mudstone pieces \\
C21 & Crest & 2137 & Light grey mudstone. Soft (conglomerate) \\
C22 & Crest & 2143 & Light grey mudstone. Soft (conglomerate) \\
\hline
\end{tabular}

\section{RESULTS AND DISCUSSION}

\section{TOC, TC and EOM in the Heidrun caprock}

The results for the extractable organic matter (EOM), corrected for loss of the light $n$-alkanes, are presented in Figure 2. The EOM values range from $2.24 \mathrm{mg} / \mathrm{g}$ rock at $2064 \mathrm{~m}$ to $6.26 \mathrm{mg} / \mathrm{g}$ rock at $2119 \mathrm{~m}$. The samples from the Crest well generally have significantly larger amounts of EOM than samples from the Flank well. The results further show a general increase in EOM with depth particularly in the Crest well. In the Flank well, on the other hand, the trend shows little temporal variation in the EOM in the mudstone sequence.

EOM is highest at the caprock/reservoir boundary (i.e. below $2100 \mathrm{~m}$ ) in the Crest well. It then gradually decreases upsection through the the caprock with the lowest values at the top (i.e. $2060 \mathrm{~m}$ ). The average EOM in the Heidrun caprock (3.16 mg/gRock) is significantly higher than the $0.5 \mathrm{mg} / \mathrm{gRock}$ background value observed to be the threshold present in caprocks (Peters, 1986). This may therefore indicate significant oil migration into the caprock at both the crest and flank of the field.

A weak positive correlation between the TOC content of the samples and the EOM is observed in both wells (Figure 3). EOM shows variation from less than $2 \mathrm{mg} / \mathrm{g}$ rock at $0.45 \% \mathrm{TOC}$, and increase to over of $6 \mathrm{mg} / \mathrm{g}$ rock for TOC contents of over $1 \%$. The weak correlation may be indicative of contribution to the EOM from external sources although differences in quality of the indigenous kerogen could also result in similar trend.

The thermal maturity proxy, Tmax, values from both the Crest and Flank wells show a general decreasing trend with increasing depth (Figure 4(a)). The maximum value of $\operatorname{Tmax}\left(433^{\circ} \mathrm{C}\right)$ is observed at a depth of 2083 $\mathrm{m}$ (i.e. within the caprock sequence) in Crest well. With increasing depth the Tmax decreases to a minimum of less than $380^{\circ} \mathrm{C}$ at $2120 \mathrm{~m}$ in the Flank well and a value of $404^{\circ} \mathrm{C}$ at the caprock/reservoir boundary $(2128$ 
$\mathrm{m})$ in the Crest well. The average Tmax for the two wells is $398^{\circ} \mathrm{C}$ and $410^{\circ} \mathrm{C}$, respectively.

In general, Tmax for source rocks increases with increasing burial depth as a result of increasing exposure to higher temperature. Depending on the kerogen type, the 'oil window' occurs between Tmax values of 435 and $470{ }^{\circ} \mathrm{C}$ and Tmax values of less than $\sim 435{ }^{\circ} \mathrm{C}$ indicate immature organic matter (Peters, 1986). However, contaminants, including oil-based drilling mud (which was not used in collecting these samples) can alter the Tmax values of the indigenous organic matter (Peters, 1986). Nevertheless, the observed Tmax values (with 398 and $410{ }^{\circ} \mathrm{C}$ averages) from both wells indicate the organic matter of the mudrock at this depth range is not thermally matured enough to be the source of the oil observed in the mudrock sequence.

\section{S1 and Production Index (PI)}

In the Crest well S1 varies from 0.1 to $2.83 \mathrm{mg} / \mathrm{gRock}$ (Figure 4) (averaging at $1.45 \mathrm{mg} / \mathrm{gRock}$ ), in response to changes in the TOC content of the samples indicating that there is some mixing between migrated oil and indigenous organic matter. The maximum S1 value (2.83 mg/gRock) is reached at the depth of $2128 \mathrm{~m}$ in the Crest well. On the other hand, in the Flank well, S1 remains almost constant (from $<0.10$ to $\sim 0.30$ with average of $0.13 \mathrm{mg} / \mathrm{gRock}$ ), again tracing the TOC trend. In this case, the maximum S1 value of 0.29 $\mathrm{mg} / \mathrm{gRock}$ is at depths of $2060 \mathrm{~m}$ at the top of the caprock. PI is used as a measure of hydrocarbon yield. A PI value of about 0.4 is reached at the base of the oil window and the hydrocarbon generative potential is exhausted at a PI value of about 1.0 (Peters, 1986). In general, a PI value of less than about 0.1 indicates immature organic matter while $\mathrm{PI}$ values greater than 0.2-0.3 for immature rocks are generally indicative of some contamination (Peters, 1986).

In the Crest well, PI values range from less than 0.4 to more than 0.8 with average at 0.54 (Figure 4). There is however no apparent trend in the distribution of PI with depth. Since both the Tmax values and the depth range of the samples indicate they are immature to generate any oil, the observed high $\mathrm{PI}$ values indicate contamination of the sequence by either migrated oil. In the Flank well the PI values are generally less than 0.3 (0.39 average) with the sample from $2060 \mathrm{~m}$ depth having the highest PI value of 0.83 . This suggests minimal surge of oil into the caprock sequence.
The high S1 and PI values of the samples from depths above $2000 \mathrm{~m}$ suggest oil staining from the reservoir since oil-based drilling fluids has not been used during drilling of the wells. This is in agreement with Noble et al. (1991) who report PI values from 0.3 to 0.4 and S1 values of no more than $1 \mathrm{mg} / \mathrm{g}$ in the mudrock of East Java where there is evidence of oil staining on the wireline log. The authors attribute the low values to the fact that absolute oil losses are minimal.

\section{Source of EOM in the Heidrun mudrock}

Figure 5 shows the relative proportions of the four petroleum fractions, namely saturated hydrocarbons, aromatic hydrocarbons, resins and asphaltenes (SARA), in the EOM of the Heidrun caprock from the two wells. The saturated and aromatic hydrocarbon fractions comprise more than $80 \%$ of the reservoir EOM. The composition of the rock extract in the Crest well shows an increase in the saturated hydrocarbon fraction with increasing depth, such that samples closer to the reservoir/caprock boundary have significantly higher proportion of the saturated hydrocarbon fractions compared to shallower samples. Caprock samples from 2050 to $2070 \mathrm{~m}$ within the caprock with less evidence of oil shows are dominated by the polar fractions. There is also similar clear systematic change in the distribution of petroleum fractions within the caprock EOM in the flank (Figure 5).

The results obtained from this study are well supported by geochemical studies present in the literature for caprocks from similar depths. Clayton and Swetland (1980) discussed the geochemistry of a number of different shales, from different depths, in the Denver Basin. They presented data from both outcrop and subcrop samples. TOC values ranges from $0.5-3.6 \%$ and EOM concentrations ranges from 88-3818 ppm in the outcrop samples. The authors report a large variation in the distribution of petroleum fractions. Specifically, the polar compounds account for $17-80 \%$ of the EOM, the saturate fractions ranges from $8-66 \%$, and the aromatic hydrocarbons are the smallest fraction accounting for only $10-34 \%$ of the EOM. They attributed the large variations to the contribution of foreign oils not indigenous to the mudrock sequences, thus suggesting a possible migration from an underlying reservoir or a migration fault route.

The sample has a TOC content of $1.8 \%$ and EOM content of 214ppm EOM/g rock; these values are in the same range as those measured in samples from the 
Heidrun caprock, and indicate that the sample has little hydrocarbon generation potential of its own. Similarly, latroscan data from the Heidrun caprock indicates that, in general the saturated and aromatic hydrocarbons accounts for more than $60 \%$ of the total EOM, whereas the combined polar fractions accounts for only about $30 \%$ of the total EOM; a clear evidence of contribution to the indigenous organic matter of the caprock.

\section{Gas wetness}

Gas wetness $\left(\% \mathrm{C}_{1} / \mathrm{C}_{1}-\mathrm{C}_{5}\right)$ range from less than $5 \%$ about $95 \%$, but most of the samples have values between $20 \%$ and $60 \%$ (Figure 6). There is a general increase in the wetness from a value of less than $30 \%$ at the reservoir/caprock interface, to over $80 \%$ at the top of the sequence before it dropped sharply to a minimum of less than $1 \%$ above the sequence.

Leith and Fallick (1995) investigating the leakage of petroleum into the Snorre caprocks, report that high gas wetness $(>50 \%)$ values coincide with the presence of oil. This is similar to what is present in the Heidrun caprock. They also show that there is a general relationship between the distribution of gaseous hydrocarbons in the caprock and the thickness and gas content of oil column; such that the petroleum of $\mathrm{C}_{2}-\mathrm{C}_{4}$ gaseous hydrocarbons into the caprock is greatest where it coincides with maximum gas-oil ratio GOR at the top of the reservoir.

The concentration of the $\mathrm{C}_{5}-\mathrm{C}_{7}$ hydrocarbons in the Heidrun ranges from less than 1 to over 120,000 ppm. The highest values of over 123,000 ppm are observed at depth of 2450 to $2260 \mathrm{~m}$, in the Fangst Group (i.e. reservoir unit) which underlies the Shetland Group. This trend also increases at the reservoir/caprock interface and then decreases gradually in the Shetland Group upwards to a value of about $48,000 \mathrm{ppm}$ in the caprock sequence and then falls to less than $10,000 \mathrm{ppm}$ above the caprock (Figure 6).

The high gas wetness of more than $80 \%$ at the top of the Shetland Group is thus a further evidence of leakage of oil from the reservoir into the overlying caprock. The high concentrations of the thermogenic $\mathrm{C}_{5}$ to $C_{7}$ (condensate hydrocarbons) $\sim 50,000 \mathrm{ppm}$ in the caprock sequence are clear indication that the oil in the caprock is not indigenous since the temperatures and depth of the caprock are below the temperatures and depths necessary for thermal cracking. The gradual decrease in the concentration of the condensates hydrocarbons from the reservoir/caprock boundary suggest fractionation along the migration route from the reservoir into the caprock which show that the oil present in the caprock came from the reservoir.

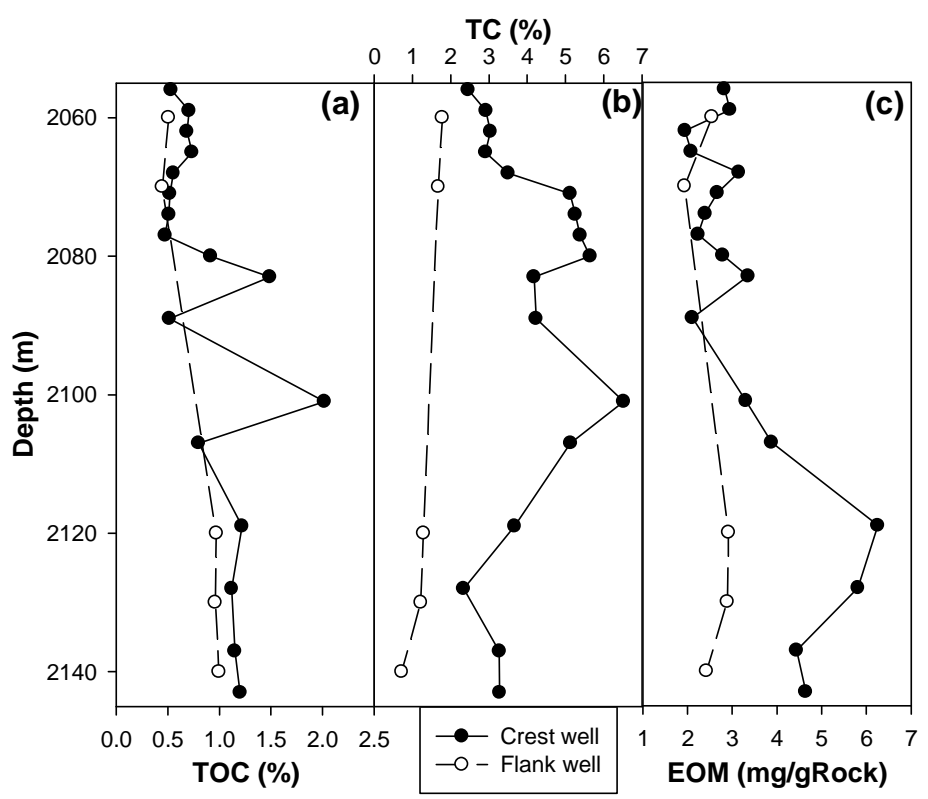

Figure 2: Plots of total organic carbon (TOC), total carbon (TC) and extractable organic matter (EOM) against depth for samples from the Crest well and Flank well in the Heidrun caprock. 


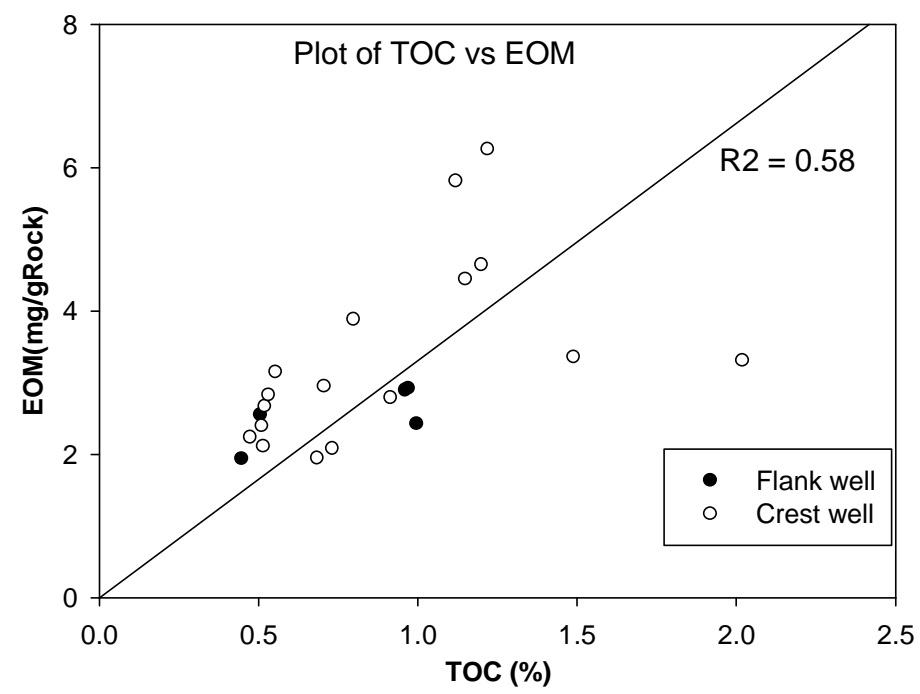

Figure 3: Total organic carbon (TOC) vs. extractable organic matter (EOM) for the Crest and Flank wells from the caprock.

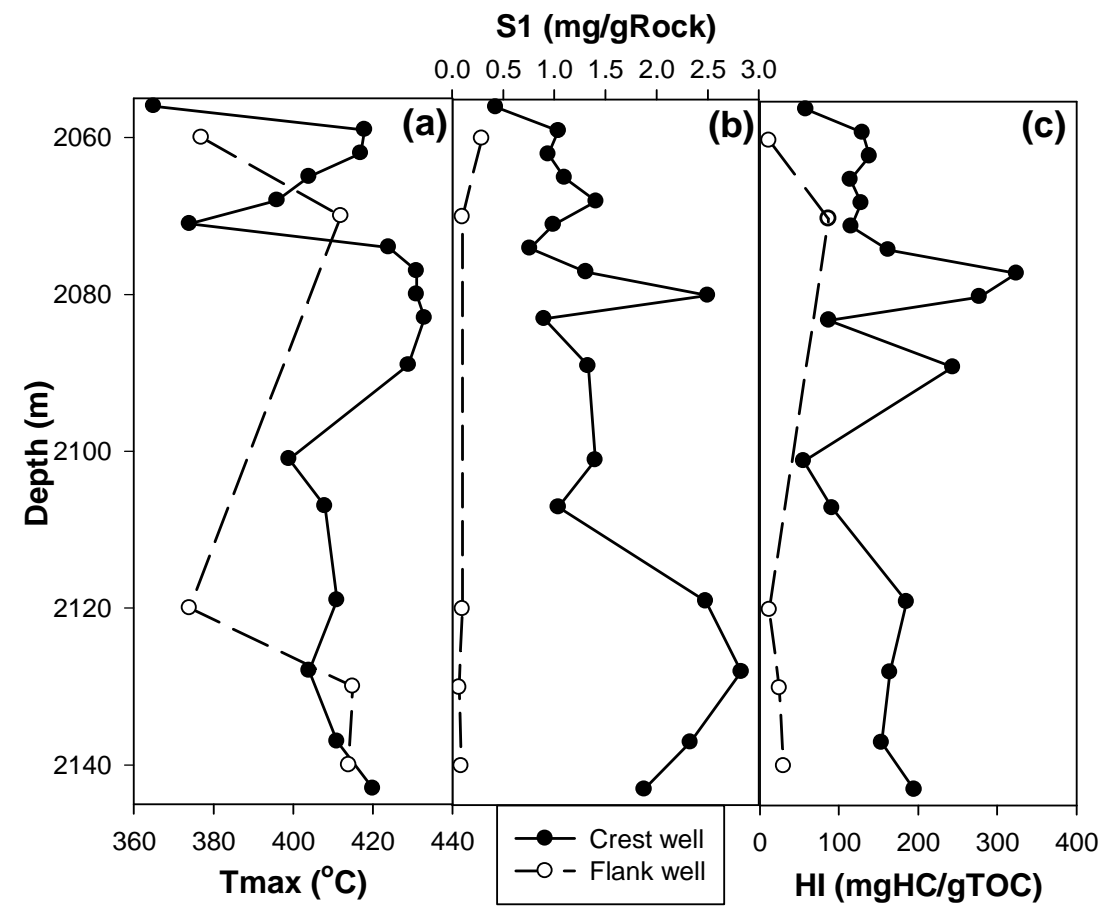

Figure 4: Plots of S1, PI and Tmax against depth for samples from the Crest well and Flank well showing that the extractable organic matter within the caprock are immature and incapable of generating oil despite evidence of oil show 

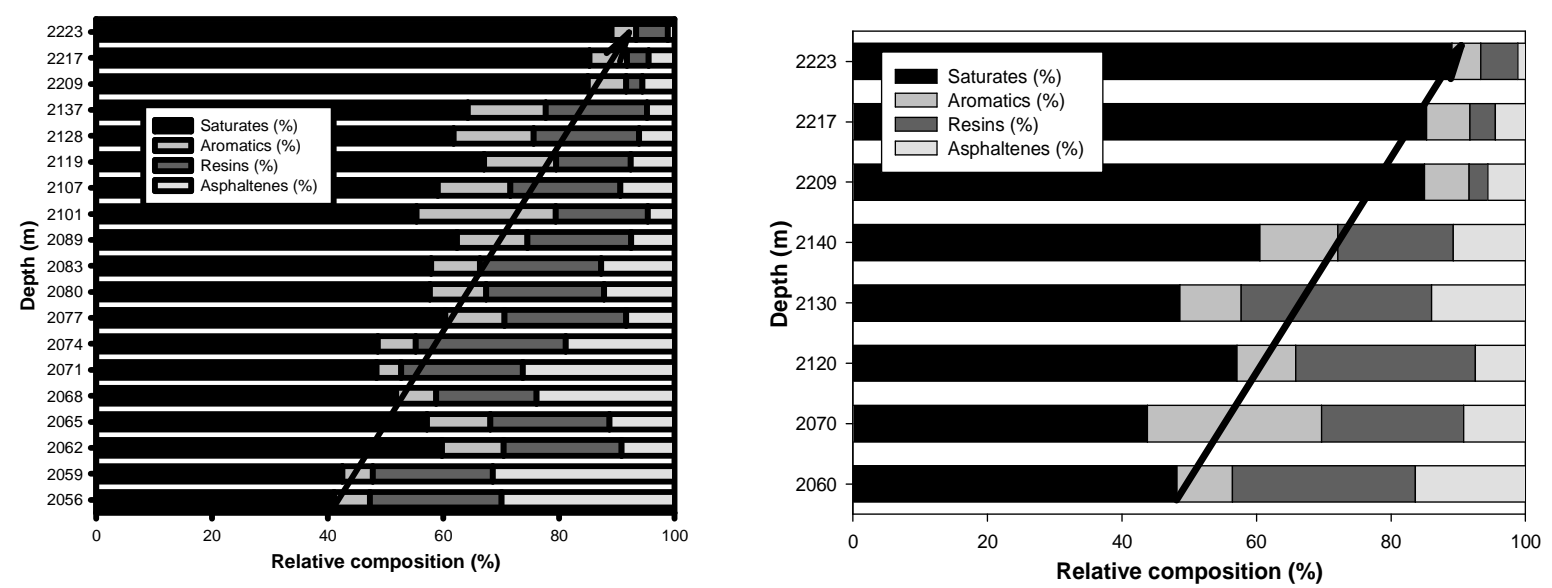

Figure 5 Petroleum fractions (as percentages) EOM from the Heidrun Crest well (a) and Flank well (b) caprocks. Samples $2127 \mathrm{~m}$ and $2223 \mathrm{~m}$ are reservoir oils showing genetic link with the mixed oil in the EOM of the caprock

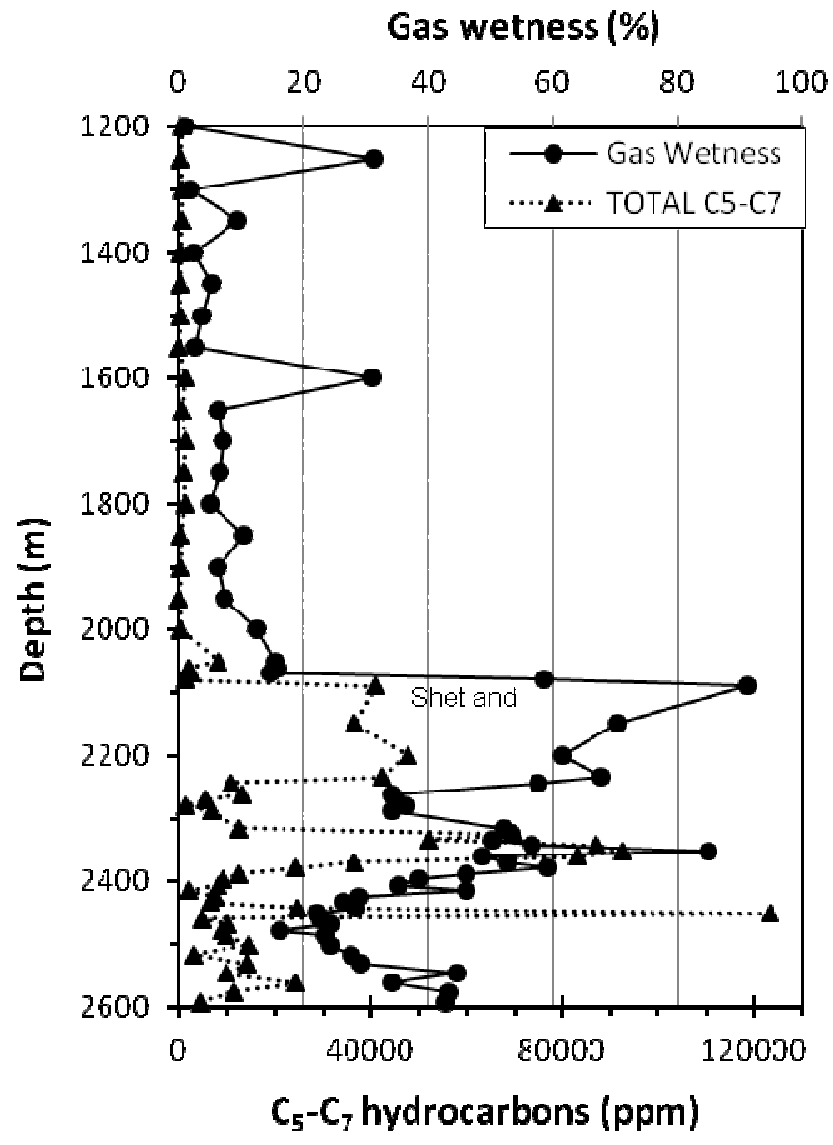

Figure 6: A plot showing change in gas wetness and concentration of condensate hydrocarbons $\left(C_{5}-C_{7}\right)$ with depth in samples from the Heidrun Formation. The horizontal lines indicate the reservoircaprock boundary. 


\section{CONCLUSIONS}

The Heidrun mud has been shown to contain little potential to generate hydrocarbons. Furthermore, it is thermally immature to convert any indigenous organic matter into the observed oil. There is significant variation in the amounts of the EOM between the Crest well and the Flank well which suggests hydrocarbon from the reservoir might have significantly contributed to the EOM in the interval sampled from the Crest well.

Furthermore, the results obtained from all the geochemical analyses of the samples from the Heidrun mud are generally in agreement in indicating that the observed oil in the caprock originates from the oil in the underlying reservoir. This further suggest failure of the caprock have occurred and may be the conduit through which the oil migrate upwards. The mechanism of this failure is the subject of another investigation and the focus of part II of this study addressed in a separate report.

\section{REFERENCES}

Bennett, B. and Later, S.R. (1997). Partition behaviour of alkylphenols in crude oil/brine systems under subsurface conditions. Geochim et Cosmochim. Acta, 61: 43934402.

Bjorkum, P.A., Walderhau, O. and Nadeau, P.H. (1998). Physical constraints on hydrocarbon leakage and trapping revisited. Petroleum Geosciences, 4: 237-239.

Clarke, R.H. and Cleverly, R.W. (1991). Petroleum seepage and post-accumulation migration, Petroleum Migration (eds: W.A. England \& A.J. Fleet). Geological Society Special Publication 59: 265-271.

Clayton, J.L. and Swetland, P.J. (1980). Petroleum Generation and Migration in Denver Basin. The American Association of Petroleum Geology Bulletin 64: 16131633.

Cooles, G.P., Mackenzie, A.S. and Quigley, T.M. (1986). Calculation of petroleum masses generated and expelled from source rocks. Organic geochemistry, 10: 235-245.

England, W.A., Mackenzie, A.S., Mann, D.M. and Quigley, T.M. (1987). The movement and entrapment of petroleum fluids in the subsurface. Journal of the Geology Society London, 144: 327-347.

Espitalie, J., Deroo, G. and Marquis, F. (1985). Rock Eval Pyrolysis and its applications. Institute Francais $d u$ Petrol, 40: 563-579.

Ingram, G.M., Urai, J.L. and Naylor, M.A. (1997). Sealing processes and top seal assessment, Hydrocarbon Seals: Importance for Exploration and Production (eds: P. Møller-Pedersen \& A.G. Koestler) NPF Special Publication, 7: 165-174.
Karlsen, D.A. and Larter, S.R. (1991). Analysis of petroleum fractions by TLC-FID: applications to petroleum reservoir description. Organic Geochemistry, 17; 603-617.

Karlsen, D.A., Nyland, B., Flood, B., Ohm, S.E., Brekke, T.I., Olsen, S. and Backer-Owe, K. (1995). Petroleum Geochemistry of the Haltenbanken, Norwegian Continental Shelf, In: Cubitt, J.M. \& England, W.A. The geochemistry of Reservoirs, Geological Society Special Publication, 86: 203-256.

Landes, K.K. (1981). Petroleum Geology, $2^{\text {nd }}$ edition, John Wiley and Sons Inc.

Larter, S.R., Taylor, P., Chen, M., Bowler, B., Ringrose, P. and Horstad, I. (1996). Secondary migration- visualizing the invisible- what can geochemistry potential do? In: Glennie, K.W. and Hurst, A. (Eds), NW Europe Industry, Geological Society of London, pp. 137-143.

Leith, T.L. and Fallick, A.E. (1995). Organic Geochemistry of cap rock hydrocarbons, Snorre Field, Norwegian North Sea, Seals traps and the petroleum system 9Ed: R.C. Surdamo. The American Association of Petroleum Geology Bulletin, 10: 29-41.

Noble, R.A., WU, C.H. and Atkinson, C.D. (1991). Petroleum generation and migration from the Talang Akar coals and shales offshore N.W. Java, Indonosia, Organic Geochemistry,17(3): 363-374.

Nordgard, B., Hege, M. and Hermanrud, C. (2002). Relationship between hydrocarbon leakage and retention capacities in the Haltenbanken and North Sea areas, offshore Norway The American Association of Petroleum Geologists in AG, 10-13 March.

Pepper, A.S. and Corvi, P.J. (1994). Simple kinetic models of petroleum formation, Part III: Modelling an open system. Marine and Petroleum Geology, 12: 417-452.

Peters, K.E. (1986). Guidelines for evaluating petroleum source rock using programmed pyrolysis. American Association of Petroleum Geology Bulletin, 70: 318-329.

Schowalter, T.T. (1979). Mechanics of Secondary Hydrocarbon Migration and Entrapment. The American Association of Petroleum Geologists Bulletin, 63: 723760.

Schowalter, T.T. and Hess, P.D. (1982). Interpretation of subsurface hydrocarbon shows. American Association of Petroleum Geology Bulletin, 66: 1302-1327.

Vik, E., Heum, O.R. and Amaliksen, K.G. (1989). Leakage from deep reservoirs: possible mechanisms and relationship to shallow gas in the Haltenbanken area, mid Norwegian Shelf, In England, W.A. \& Fleet, A.J. (eds). Petroleum Migration Geological society, Special Publication, 59: 273.

Whitley, P.K. (1992). The Geology of Heidrun: A giant oil and gas field on the mid-Norwegian shelf, In: AAPG Giant oil and Gas Fields of the decade 1980-1990. 